\title{
Experimental Study on Autoclaved Aerated Concrete under Uniaxial Compression
}

\author{
WANG Bo ${ }^{1,}$ a , WANG Hong ${ }^{2, ~ b}$, KONG Xinli ${ }^{1, c}$, DUAN Liqun ${ }^{1, d}$
}

${ }^{1}$ State Key Laboratory of Disaster Prevention \& Mitigation of Explosion \& Impact, Army Engineering University, Nanjing 210007, China

${ }^{2}$ Beijing Canbao Architec Design Institute, Beijing 100036, China

a wbo5503@163.com, bwwanghong80@126.com, ${ }^{c}$ 75974502@qq.com, d850082427@qq.com

Keywords: Strain rate, Autoclaved Aerated Concrete (AAC), Compressive strength.

Abstract. A total of 60 cylindrical specimens with density of $425 \mathrm{~kg} / \mathrm{m}^{3}, 525 \mathrm{~kg} / \mathrm{m}^{3}$, and $625 \mathrm{~kg} / \mathrm{m}^{3}$, subjected to uniaxial compression were tested, under four different strain rates ranging from $10^{-5} / \mathrm{s}$ to $10^{-2} / \mathrm{s} .15$ specimens designed and casted on the same condition were tested for every set of case. The mean and standard variation values of the uniaxial compressive stress-strain curves, as well as the statistical characteristic values of compressive stress and peak strain of concrete with different strength under different strain rates, were obtained through experiments. The results indicate that the strain rate has a significant influence on the stress-strain mean value curves.

\section{Introduction}

As a kind of ultra-light porous material, autoclaved aerated concrete (AAC) has the advantage of light quality, heat preservation, sound insulation, environmental friendly and other advantages, and its manufactured goods has integrated molding, the craft is simple, the price is low. Therefore, AAC has been widely used as building cladding, vibration isolation filling material. The AAC and its properties of material mechanics are the research achievements of rich manufactured goods ${ }^{[1-5]}$. But the strain rate effect of AAC study is less, the whole process of the nature of investigation under dynamic loading condition is the lack of adequate experimental data.

This article is in view of the AAC under uniaxial compression, the variation values of the uniaxial compressive stress-strain curves, as well as the statistical characteristic values of compressive stress and peak strain of concrete with different strength under different strain rates, were obtained through series of experiments.

\section{Specimens and the testing facilities}

Specimens design. The testing AAC used is commercial concrete in practical engineering, made by Nanjing Xujian New Building Materials Company. Specimens were in three density: $425 \mathrm{~kg} / \mathrm{m}^{3}$ (AAC425), $525 \mathrm{~kg} / \mathrm{m}^{3}$ (AAC525), $625 \mathrm{~kg} / \mathrm{m}^{3}$ (AAC625), with diameter of $50 \mathrm{~mm}$ and $100 \mathrm{~mm}$ high cylinder.

Testing facilities. Test equipment for the MTS company CDT1504 type motor servo system. The system includes loading system, controller, measurement system, etc., the loading speed is 0.06 $\mathrm{mm} / \mathrm{min}-60 \mathrm{~mm} / \mathrm{min}$, the maximum pressure of 5 tons. Range of the system and test the pressure value is more matching, high measurement accuracy.

Measurement system consists of DCS - 300 automatic measurement system (which can record pressure and displacement real-time data), and strain measurement system. Strain signal acquisition system adopts DH8302 signal test and analysis system made by Donghua Testing Instrument Factory, the sampling frequency was set to $200 \mathrm{~Hz}$. Strain gauges were arranged at the middle point of the specimen in length symmetrically. Strain data adapted was the average value of the two strain gauges' measurement, which could reduce the influence of bending deformation caused by specimen eccentric force. 


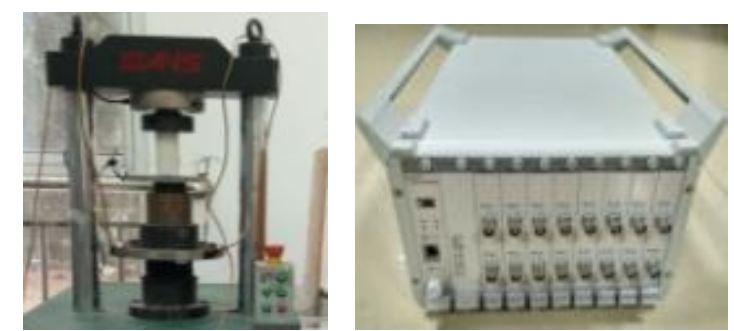

Fig.1 Test loading and strain measurement system

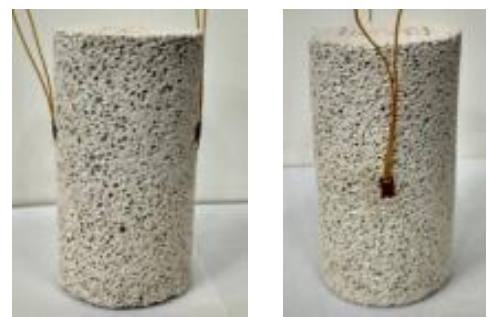

Fig.2 Arrangement of strain gage

Testing methods. According to different densities of concrete, the specimens were tested in three groups. And in each group, the specimens' stress-strain full curves at four loading rate of 0.06 $\mathrm{mm} / \mathrm{min}, 0.6 \mathrm{~mm} / \mathrm{min}, 6 \mathrm{~mm} / \mathrm{min}$, and $60 \mathrm{~mm} / \mathrm{min}$ were obtained. With the same density and loading rate for 5 groups of test specimens, a total of 60 effective experimental results were recorded. The specific loading rate, parameters such as test specimens are shown in table 1.Uniaxial compression tests on specimens completely destroyed, the load was stopped when it was less than $40 \%$ of the peak pressure and stable, the specimens were completely destroyed. As shown in Fig. 3 (a) - (e), specimen's failure form is vertical splitting, failure process is: one or a small amount of a slight vertical stripes, crack expansion, more rapid development throughout the specimen crack and crack. Notably, a handful of specimen's damage form was as shear failure, as shown in Fig. 3 (f).

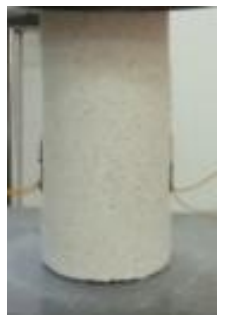

( a )

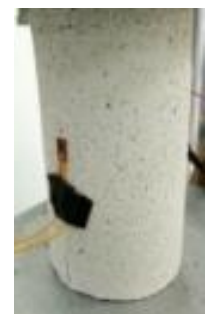

( b )

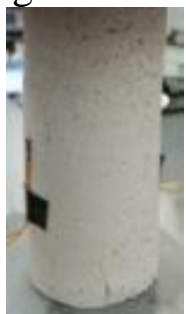

( c )

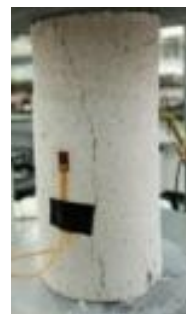

(d)

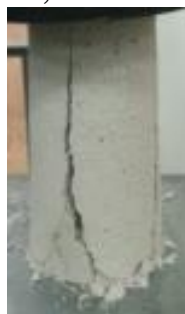

( e )

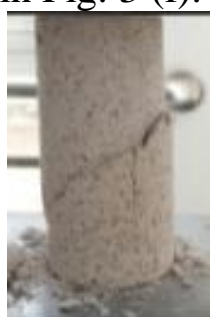

( f )

Fig.3 Destruction course of a specimen under unixial pressure

Table 1 Summary of uniaxial compression tests on specimens

\begin{tabular}{ccccccc}
\hline No. & $\begin{array}{c}\text { Loading rate } \\
(\mathrm{mm} / \mathrm{min})\end{array}$ & Strain rate $\left(\mathrm{s}^{-1}\right)$ & \multicolumn{4}{c}{ Amount of specimen } \\
\hline 1 & 0.06 & $1 \times 10^{-5}$ & 5 & 5 & 5 & 15 \\
2 & 0.6 & $1 \times 10^{-4}$ & 5 & 5 & 5 & 15 \\
3 & 6 & $1 \times 10^{-3}$ & 5 & 5 & 5 & 15 \\
4 & 60 & $1 \times 10^{-2}$ & 5 & 5 & 5 & 15 \\
\hline
\end{tabular}

Table 2 Uniaxial compression stress of AAC

\begin{tabular}{cccccccccc}
\hline Density & $\begin{array}{c}\text { Strain } \\
\text { rate } \varepsilon\end{array}$ & \multicolumn{1}{c}{ Testing value of peak stress $(\mathrm{MPa})$} & $\begin{array}{c}\text { Mean value of } \\
\text { peak stress } \\
(\mathrm{MPa})\end{array}$ & $\begin{array}{c}\text { Standard } \\
\text { deviation }\end{array}$ & $\begin{array}{c}\text { Dynamic } \\
\text { enhancement } \\
\text { factor } F_{D}\end{array}$ \\
\hline & $10^{-5} / \mathrm{s}$ & 2.09 & 2.08 & 2.11 & 2.19 & 2.20 & 2.13 & 0.057 & 1 \\
425 & $10^{-4} / \mathrm{s}$ & 2.46 & 2.89 & 2.15 & 2.21 & 2.65 & 2.47 & 0.308 & 1.160 \\
$\mathrm{~kg} / \mathrm{m}^{3}$ & $10^{-3} / \mathrm{s}$ & 2.70 & 3.01 & 2.98 & 2.62 & 2.80 & 2.82 & 0.171 & 1.324 \\
& $10^{-2} / \mathrm{s}$ & 3.00 & 3.48 & 2.80 & 3.01 & 2.71 & 3.00 & 0.298 & 1.408 \\
& $10^{-5} / \mathrm{s}$ & 2.98 & 3.87 & 2.72 & 2.77 & 2.79 & 2.83 & 0.482 & 1 \\
525 & $10^{-4} / \mathrm{s}$ & 4.01 & 3.35 & 3.60 & 3.91 & 3.88 & 3.75 & 0.270 & 1.325 \\
$\mathrm{~kg} / \mathrm{m}^{3}$ & $10^{-3} / \mathrm{s}$ & 4.07 & 3.60 & 4.34 & 3.53 & 4.02 & 3.91 & 0.340 & 1.382 \\
& $10^{-2} / \mathrm{s}$ & 4.51 & 4.49 & 4.50 & 4.28 & 4.68 & 4.49 & 0.142 & 1.587 \\
& $10^{-5} / \mathrm{s}$ & 4.27 & 5.18 & 3.90 & 4.02 & 3.95 & 4.26 & 0.531 & 1 \\
625 & $10^{-4} / \mathrm{s}$ & 4.69 & 4.53 & 4.63 & 4.65 & 4.70 & 4.64 & 0.068 & 1.089 \\
$\mathrm{~kg} / \mathrm{m}^{3}$ & $10^{-3} / \mathrm{s}$ & 5.30 & 5.32 & 5.12 & 4.90 & 4.85 & 5.10 & 0.219 & 1.197 \\
& $10^{-2} / \mathrm{s}$ & 5.95 & 5.61 & 5.86 & 5.60 & 5.77 & 5.76 & 0.154 & 1.352 \\
\hline
\end{tabular}




\section{Experimental results and analysis}

Stress-strain curve. Totally 60 stress-strain curves of the specimens were obtained as mentioned above. The testing results were discrete because of specimens' defects themselves, the differences in the shape of the specimens, etc. as shown in Tab. 2. Other than testing values, the mean value and standard deviation of peak stress is also demonstrated in Tab. 2. As the stress-strain curve of the specimens with different densities were similar, AAC 525 is taken as an example here. As shown in Fig. 4, the stress-strain curve of AAC 525 under the static load with strain rate of $10^{-5} / \mathrm{s}$. It is visible from the figure, that the compression curve can be divided into four sections: (1) Segment OA, compaction stage, the curve is slightly upward. That phenomenon was believed to be caused by the densification of the porous structure within concrete under pressure ${ }^{[6]}$. (2) Segment AB, straight line stage, it is approximate to linear elastic. The stress value at point $\mathrm{A}\left(\sigma_{A}\right)$ is about $20 \%$ of the maximum stress value $\left(\sigma_{\max }\right)$. The stress value at point $\mathrm{B}\left(\sigma_{B}\right)$ is about $60 \%$ of the maximum stress value. (3) Segment BC, inelastic stage, the curve is bending down. Within the segment, parallel to the direction of the load gradually generates invisible micro cracks, and point B is the turning point of elastic stage and inelastic stage. (4) Segment CD, failure stage, stress of specimen is gradually declined, the stress value at point $\mathrm{C}$ is the uniaxial compressive strength $\left(R_{c}\right)$ of the specimen.

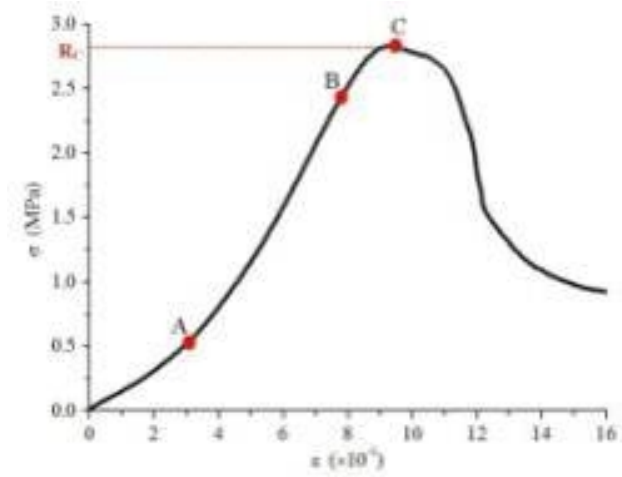

Fig.4 Mean stress-mean strain curve of AAC525

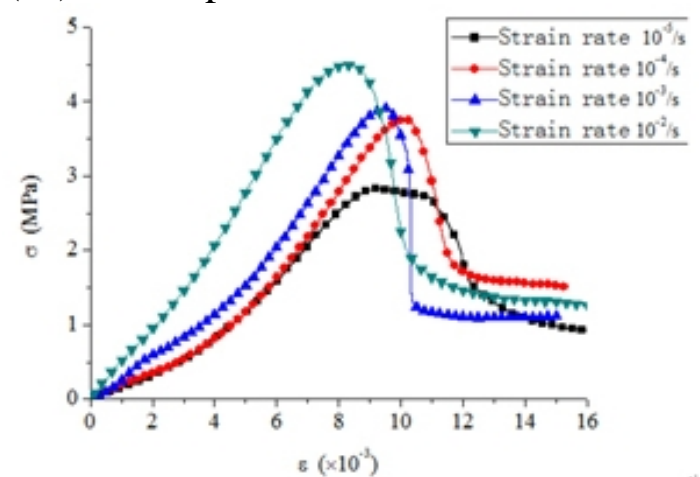

Fig.5 Mean stress-strain curve of AAC 525

Elasticity modulus. Based on the literature ${ }^{[6,7]}$, material elastic modulus should select stress-strain curve linear elastic stage, which is the slope of segment $\mathrm{AB}$ as the testing value of material elastic modulus. As for rock and ordinary concrete, the slope of the secant between point $\mathrm{A}$ and point $\mathrm{B}$ should be chosen as the testing elastic modulus. The testing results of $\sigma_{A} / \sigma_{\max }$ and $\sigma_{B} / \sigma_{\max }$ are listed in table 3. As the testing result shows that the $\sigma_{A} / \sigma_{\max }$ and $\sigma_{B} / \sigma_{\max }$ of AAC is about $30 \%, 80 \%$ respectively, the value of latter is $10 \%$ higher than that of normal concrete, namely the AAC elastic modulus calculated value should take stress extreme value of $30 \%-80 \%$ is reasonable. AAC425, AAC525, AAC625 elastic modulus were $0.34 \mathrm{GPa}, 0.57 \mathrm{GPa}, 0.73 \mathrm{GPa}$, the elastic modulus of AAC as it increases with the increase of density.

Table 3 Testing results of AAC's elastic modulus

\begin{tabular}{ccccccc}
\hline Density & Strain rate & \multicolumn{2}{c}{$\sigma_{A} / \sigma_{\max }$} & \multicolumn{2}{c}{$\sigma_{B} / \sigma_{\max }$} & Elasticity \\
$\rho$ & $\varepsilon$ & Testing value & Mean value & Testing value & Mean value & modulus $E_{C}$ \\
\hline & $10^{-5} / \mathrm{s}$ & $28 \%$ & & $78 \%$ & & \\
425 & $10^{-4} / \mathrm{s}$ & $24 \%$ & $25.3 \%$ & $85 \%$ & $79.6 \%$ & $0.34 \mathrm{GPa}$ \\
$\mathrm{kg} / \mathrm{m}^{3}$ & $10^{-3} / \mathrm{s}$ & $30 \%$ & & $79 \%$ & & \\
& $10^{-2} / \mathrm{s}$ & $19 \%$ & & $78 \%$ & & \\
& $10^{-5} / \mathrm{s}$ & $22 \%$ & & $87 \%$ & & \\
525 & $10^{-4} / \mathrm{s}$ & $38 \%$ & $30 \%$ & $87 \%$ & $90.1 \%$ & $0.57 \mathrm{GPa}$ \\
$\mathrm{kg} / \mathrm{m}^{3}$ & $10^{-3} / \mathrm{s}$ & $33 \%$ & & $94 \%$ & & \\
& $10^{-2} / \mathrm{s}$ & $27 \%$ & & $92 \%$ & & \\
& $10^{-5} / \mathrm{s}$ & $28 \%$ & & $82 \%$ & & \\
625 & $10^{-4} / \mathrm{s}$ & $23 \%$ & $24.6 \%$ & $79 \%$ & $81.3 \%$ & $0.73 \mathrm{GPa}$ \\
$\mathrm{kg} / \mathrm{m}^{3}$ & $10^{-3} / \mathrm{s}$ & $22 \%$ & & $80 \%$ & & \\
& $10^{-2} / \mathrm{s}$ & $25 \%$ & & $84 \%$ & & \\
\hline
\end{tabular}


Influence of density. Fig. 6 shows the mean value of stress-strain curve of AAC with different densities under uniaxial compression. It is clear that under the four kinds of loading rate, the higher of the density, the higher of the compressive strength of concrete. For instance, under static load (strain rate of $\left.10^{-5} / \mathrm{s}\right)$, AAC625 compressive strength (4.26 MPa) twice as high as AAC425 (2.13 MPa). But at the same time, with the increase of density, brittle character of materials is more obvious. Due to the higher density of concrete, the lower the porosity, the more concentrated the intensity distribution of materials, the faster can lead to the development of fracture damage, so the stress-strain curve more steep decline period, showed an evident in the brittle characteristics.

Influence of strain rate. Strain rate is the characterization of the deformation velocity of a measure. Generally considered traditional coarse grained material is not sensitive to strain rate, and the foam is not the case. Usually foam under high strain rate can obtain higher intensity. Specific mechanisms different literature explanation, but overall there is no unified understanding. Uniaxial compressive strength of the incentive factors FD is one of the important indicators to measure strain rate effect of concrete, which is defined as:

$$
F_{D}=\sigma_{\mathrm{d}, \max } / \sigma_{\mathrm{s}, \max }
$$

where $\sigma_{d, \max }$ is peak stress of concrete under dynamic action, $\sigma_{s, \max }$ is peak stress of concrete under static compressive load.

Uniaxial compressive strength of the incentive factors are shown in table 2, the dynamic increase factor increased with the increase of strain rate increase. As shown in Fig. 5, as the density of the same specimen (AAC525) under different loading rate of the mean stress - strain curve. By the figure can be seen, AAC under uniaxial compressive stress-strain relationship affected by loading rate.

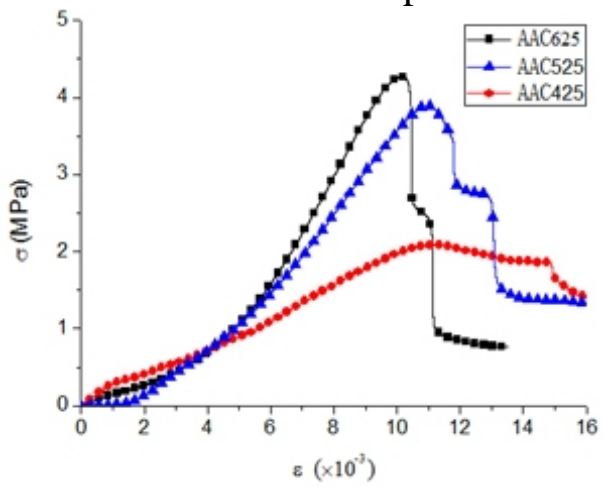

Fig.6 (a) Stress-strain curve at strain rate of $10^{-5} / \mathrm{s}$

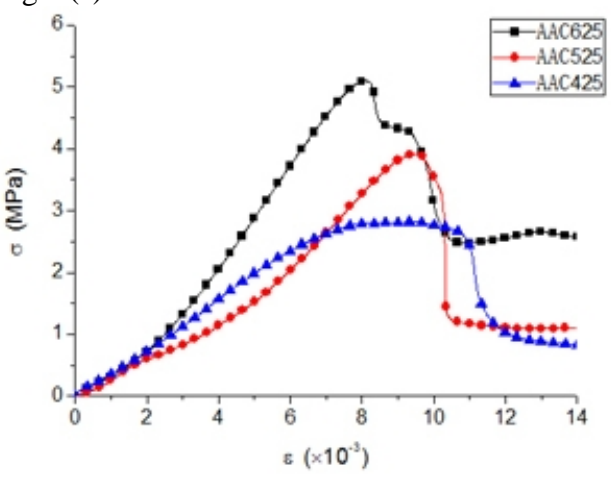

Fig.6 (c) Stress-strain curve at strain rate of $10^{-3} / \mathrm{s}$

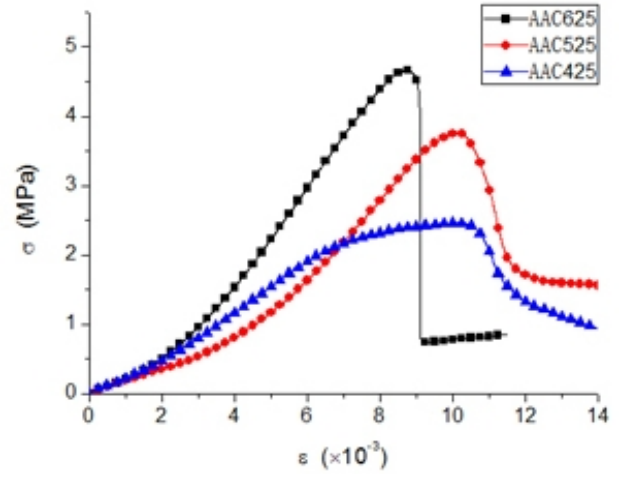

Fig.6 (b) Stress-strain curve at strain rate of $10^{-4} / \mathrm{s}$

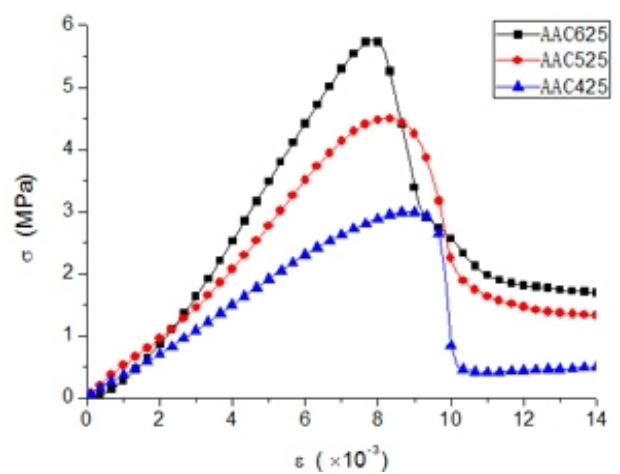

Fig.6 (d) Stress-strain curve at strain rate of $10^{-2} / \mathrm{s}$

Influence of strain rate on the peak strain. In order to study the effect of strain rate on the peak strain, test the AAC strain under different loading conditions. The average maximum strain of each test listed in table 4.The statistical result shows that the mean peak strain of AAC decreases with the increase of strain rate, strain rate increased from $10^{-5} / \mathrm{s}$ to $10^{-2} / \mathrm{s}$, the peak strain reduced from 11.29 $\times 10^{-3}$ to $8.83 \times 10^{-3}$, reduced by $27.9 \%$. So, within the scope of strain rate from $10^{-5} / \mathrm{s}$ to $10^{-2} / \mathrm{s}$, the peak strain of the strain rate effect is obvious. 
Concrete density is relatively significant influence on the peak strain. As shown in Fig. 6, under the same loading rate, peak strain specimen with the loss of the concrete density and higher. Low density, porosity is larger, which resulted in increased peak strain.

Table 4 Summary on mean values of AAC's peak strain

\begin{tabular}{cccc}
\hline Strain rate & AAC 425 & AAC 525 & AAC 625 \\
\hline $10^{-5} / \mathrm{s}$ & $11.29 \times 10^{-3}$ & $10.97 \times 10^{-3}$ & $10.15 \times 10^{-3}$ \\
$10^{-4} / \mathrm{s}$ & $10.23 \times 10^{-3}$ & $9.56 \times 10^{-3}$ & $8.74 \times 10^{-3}$ \\
$10^{-3} / \mathrm{s}$ & $9.51 \times 10^{-3}$ & $8.54 \times 10^{-3}$ & $8.09 \times 10^{-3}$ \\
$10^{-2} / \mathrm{s}$ & $8.83 \times 10^{-3}$ & $8.33 \times 10^{-3}$ & $7.33 \times 10^{-3}$ \\
\hline
\end{tabular}

\section{Conclusions}

In this investigation, a total of 60 cylindrical specimens with density of $425 \mathrm{~kg} / \mathrm{m}^{3}, 525 \mathrm{~kg} / \mathrm{m}^{3}$, and $625 \mathrm{~kg} / \mathrm{m}^{3}$, subjected to uniaxial compression were tested, under four different strain rates ranging from $10^{-5} / \mathrm{s}$ to $10^{-2} / \mathrm{s}$. The failure process, peak stress and modulus of elasticity, strain rate sensitivity were analyzed, the results shows that:

(1) The stress-strain full curve of AAC with same density is discrete. The difference can be averaged through multiple sets of tests to improve the reliability of testing results.

(2) The AAC's stress-strain curve of elastic stage is shorter than ordinary concrete or rock, the elastic modulus of AAC's elastic modulus calculated value should take stress extreme value of $30 \%$ $80 \%$ is reasonable.

(3) The compressive strength of AAC has obvious strain rate effect. The greater the loading rate, the higher the peak stress and decline period of the stress curve is steep, brittle performance is more obvious.

(4) The peak strain of the AAC strain rate effect is more apparent, the mean peak strain decreases with the increase of strain rate. While the peak strain of the AAC increases with the reduction of density porosity increases.

\section{References}

[1] Snow C. A comprehensive study of the material properties and structural behavior of AAC products [D]. M.S. thesis. University of Alabama at Birmingham , 1999

[2] AmolK. Structural characterization of hybrid fiber reinforced polymer(FRP) Autoclaved Aerated Concrete (AAC) panels[D]. M.S. thesis. University of Alabama at Birmingham; 2004.

[3] MousaMA, UddinN. Experimental and analytical study of carbon fiber-reinforced polymer (FRP)/autoclaved aerated concrete (AAC) sandwich panels[J]. Engineering Structure , 2009 , $31: 2337-2344$

[4] BonakdarA , BabbittF , MobasherB. Physical and mechanical characterization of fiber-reinforced aerated concrete (FRAC) [J]. Cement Concrete Composition , 2013 , 38:82-91.

[5] Dey V, Zani G, Colombo M, et al. Flexural impact response of textile-reinforced aerated concrete sandwich panels [J]. Materials and Design , 2015 , 86:187-197.

[6] Zhang Yongxing , Xu Ming , He Yongnian. Rock Mechanics ( The third edition ) [M]. Beijing : China Building Industry Press , 2015.

[7] Ministry of Electricity Industry of P.R.C. Standard for engineering rock mass test : GB/T 50266-1999 [S]. Beijing: China Standards Press, 1999. 